\title{
INFÂNCIA E CIDADE: UM CAMPO DE ESTUDO EM DESENVOLVIMENTO
}

\author{
FERNANDA MÜLLER* \\ Brasilmar Ferreira Nunes*
}

RESUMO: Discutimos no artigo, em forma de ensaio teórico, a especificidade da temática infância e cidade, utilizando recortes analíticos oriundos das Ciências Sociais. O artigo é organizado em três seçôes. A primeira explora os paradigmas nas Ciências Sociais e de que forma eles se atentam para as crianças e a infância. Na segunda seção, a temática infância e cidade é tratada, tendo como base teórica autores clássicos da Escola de Chicago, comungados com autores contemporâneos que refletem sobre esta relação. Já na terceira seção observamos as interaçóes das crianças no meio urbano; o potencial de uso e apropriação da cidade pelas crianças é contrastado com o poder do adulto. Ao problematizar esses três aspectos avançamos na compreensão da relação entre infância e cidade e sugerimos a necessidade de transformá-la em uma linha de pesquisa.

Palavras-chave: Cidade. Educação. Infância. Sociologia da Infância. Sociologia Urbana.

\section{THE CHILDHOOD AND THE CITY: AN ACADEMIC FIELD IN DEVELOPMENT}

ABSTRACT: We discuss in this paper, presented as a theoretical essay, the specificity of the thematic the childhood and the city, using analytical framework from the Social Sciences. The article is organised in three sections. The first one explores the Social Sciences paradigms and in which ways they are connected to the children and childhood. The second section explores the thematic childhood and the city, considering authors from the Chicago School and contemporary ones. In the third section we observe the children`s interactions in the urban context; the potential of use and appropriation of the city by the children is contrasted with the adult power. Problematizing these three aspects we can understand better the relationship between childhood and the city, and we suggest the need of transforming it in a research line.

Keywords: City. Education. Childhood. Sociology of Childhood. Urban Sociology.

\footnotetext{
* Universidade de Brasília, Faculdade de Educação, Brasília, Distrito Federal, Brasil. E-mail de contato: fernanda.muller@gmail.com.

** Universidade de Brasília, Instituto de Ciências Sociais, Departamento de Sociologia, Brasília, Distrito Federal, Brasil.
} 


\section{L`ENFANCE ET LA VILLE: UN CHAMP ACADÉMIQUE EN DÉVELOPPEMENT}

RÉSUMÉ: L'article, en forme d'essai, discute de façon théorique et méthodologique l'espécificité de la thématique enfance et ville en utilisant des coupures analytiques venant de la sociologie et de l'éducation. La thématique enfance et ville est exploitée ayant comme base théorique les auteurs classiques de l'École de Chicago en partenariat avec des auteurs actuels qui réfléchissent sur ce sujet. On observe que la socialisation de l'enfant dans un milieu urbain se déroule dans un territoire socialement hétérogène à travers plusieurs processus. Le potentiel de l'usage et l'appropriation de la ville par les enfants se présentent donc limités et fragmentés. En réfléchissant cette fragmentation nous avançons des aspects qui aident dans la compréhension de l'intersection des deux variables.

Mots-clés: Ville. Éducation. Enfance. Sociologie de l'Enfance. Sociologie Urbaine.

\section{Introdução}

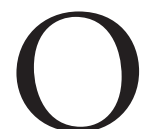

Estatuto da Criança e do Adolescente (BRASIL, 1990) define como criança meninos e meninas de até 12 anos de idade incompletos. Se considerarmos o recorte de zero a onze anos verificamos que $29 \mathrm{mi}-$ lhôes de crianças brasileiras vivem em áreas urbanas, perfazendo um percentual de 81\% (IBGE, 2010) da população dessa faixa etária. Este dado nos motiva a pensar sobre as infinitas possibilidades de pesquisa sobre os mundos sociais das crianças em cidades e alinha-se com o argumento de Prout (2003, p. xv), de que, "Para milhóes de crianças os contornos de suas vidas cotidianas e experiências são (em parte) moldados pelos ambientes da cidade."

O presente artigo, na forma de ensaio teórico, defende a especificidade no trato da temática infância e cidade, pensada aqui através dos campos - no sentido dado por Bourdieu (2007) - da Sociologia e da Educação. Sugerimos que a Sociologia, assim como as subáreas dela decorrente que se dedicam ao estudo do urbano e da infância podem, de forma encadeada e coesa, apresentar contribuiçóes para uma linha de pesquisa em consolidação.

Investigar a vida das crianças nas cidades demanda um duplo compromisso de pesquisa, tanto acadêmico-científico, como político. Do ponto de vista acadêmico, Christensen e O'Brien (2003, p. 1) introduzem novas perspectivas sobre o estudo das crianças na cidade, sugerindo três temas-chave desta relação, quais sejam: 1) incluir as crianças no debate diz respeito a entender a vida da cidade a partir do ponto de vista delas; 2) justapor conexóes entre lar, vizinhança, comunidade e cidade, o que diz respeito à interação contínua de redes de rela- 
ções, lugares e espaços para crianças e adultos; e 3) promover o engajamento das crianças em processos de mudança das cidades compreende saber como crianças veem a cidade, que por sua vez, poderão ser transformadas a partir de um quadro sensível às crianças. Certamente essas orientaçóes deverão estar na base dos estudos urbanos sobre a infância.

Christensen e O’Brien (2003) reconhecem em Colin Ward um de seus inspiradores. No clássico The Child in the City, Ward (1978, p. vi) chama a atenção para o compromisso político, argumentando que "[...] a ligação entre a cidade e a criança pode ser mais proveitosa e agradável para a criança $e$ para a cidade [...]" (grifo do autor). Todavia, para penetrar os mundos sociais das crianças na cidade, é necessário reconhecer que suas experiências são variadas, indiscriminadas, que nem sempre seguem as associaçóes mentais convencionais dos adultos. (WARD, 1978, p. 22) Além do mais, é necessário ao pesquisador utilizar de mecanismos diferenciados de comunicação com a criança, o que viabiliza a compreensão de suas necessidades e experiências.

A concepção de criança como um ser incapaz, passivo e completamente dependente é maximizada quando deslocamos o nosso olhar para o contexto da vida pública, para o espaço da cidade. Isto pode ser tanto observado na própria tradição sociológica ${ }^{1}$ bem como no mundo social, principalmente no comportamento dos adultos em relação à criança nos médios e grandes centros urbanos. Por outro lado, a própria relação estabelecida entre a criança e a cidade nos mostra um jogo complexo, de duas vias:

[...] afastados das esferas institucionalizadas de poder, crianças e jovens embatem, na tessitura física e social por onde a vida da cidade se constrói, um jogo de forças para ocuparem seu lugar enquanto sujeito coletivo. (CASTRO, 2004, p. 19)

É este fenômeno que faz da cidade um privilegiado campo de pesquisa sobre a infância.

$\mathrm{Na}$ tentativa de circunscrever a temática proposta, tratamos da criança no espaço público como agente ativo nas interaçôes estabelecidas na cidade, no sentido dado por Goffman (1989). Reconhecemos os limites de teorizar a infância a partir de dicotomias construídas na comparação com o mundo adulto (natureza $v s$. cultura; vida privada $v s$. vida pública; incompetência vs. competência; dependência $v s$. autonomia; etc.), assim como não é suficiente analisar a cidade somente através de suas funçóes.

Dessa maneira, construímos na primeira seção deste artigo um quadro teórico explicativo dos paradigmas das Ciências Sociais, apontando lacunas e possibilidades para os estudos da relação entre infância e cidade. $\mathrm{Na}$ segunda seção 
empreendemos um olhar atento a algumas construçóes teóricas relacionadas aos conceitos de infância e cidade. Na terceira seção abordamos as múltiplas interações possibilitadas ou limitadas na relação da criança com a cidade. Finalmente, nas conclusóes, sintetizamos os principais argumentos discutidos ao longo do texto.

\section{Os paradigmas nas Ciências Sociais}

Na trajetória do campo social - como de resto em todos os campos disciplinares ou científicos - as reflexóes pertinentes se fazem a partir de paradigmas científicos que definem normas orientadoras, estabelecendo limites que determinam como pesquisadores devem agir. Kuhn (1962) ${ }^{2}$ argumenta que o paradigma é um princípio, que tanto pode ser teórico ou originado de pesquisas em determinado campo científico, o qual servirá de modelo para novas pesquisas. As Ciências Sociais, ao contrário das chamadas hard sciences, são multiparadigmáticas, no sentido em que detêm vários princípios analíticos, não se submetendo exclusivamente a um deles. Assim, podemos retomar os argumentos de Caillé (1998, p. 7), que se referindo às Ciências Sociais considera que o paradigma é "[...] simplesmente um modo generalizado e mais ou menos inconscientemente compartilhado de questionar a realidade social histórica e de conceber respostas para essas questões".

Mesmo tomando essa assertiva como base, temos ainda que considerar que nas ciências da sociedade há uma equação de fundo que nos obriga a tomar partido em termos metodológicos, e porque não dizer, ideológicos. Estamos nos referindo à equação indivíduo vs. sociedade, que pressupóe questóes que podem intervir nos parâmetros analíticos que adotemos. São dois polos de uma equação que estão na origem do pensamento social e quando olhada a partir de suas partes componentes (ou indivíduo, ou sociedade) corroboram a construção de dois paradigmas básicos que orientam estudos no campo social, são eles: o individualismo metodológico e o holismo. Esta equação que com frequência é lida como oposição, pertencente a campos opostos e antagônicos, termina por dificultar a compreensão da sua dinâmica.

O individualismo metodológico pode ser definido como

[...] a doutrina de que todos os fenômenos sociais - sua estrutura e sua mudança - são em princípio explicáveis por fatores que envolvem apenas os indivíduos - suas propriedades, seus objetivos, suas crenças e suas açóes [...]. (ELSTER, 1985, p. 5)

Ele compartilha com o atomismo a concepção de que a explicação sociológica é, em última instância, redutível ao nível individual. De fato, estamos 
tratando aqui de uma relação concreta que, por efeito analítico, termina por se converter em abstrações onde as duas variáveis se excluem e carregam em si componentes de oposiçáo e conflito. Os indivíduos têm tanto propriedades (crenças, habilidades, recursos) quanto entram numa diversidade de relaçóes com outros indivíduos (de parentesco, de patrão-empregado etc.). Portanto, as questóes de fundo por detrás dessa equação de variáveis relacionais articulam dimensóes diversas, tais como: o individual e o social, o singular e o universal, o particular e a cultura, com evidente sobrecarga decorrente das realidades às quais elas se referem concretamente.

Assim, o individualismo metodológico tem como ponto primeiro o pressuposto de que as relaçóes sociais são vinculadas, na sua origem, à ação individual, cuja somatória produziria aquilo que chamamos sociedade. Não há aqui, portanto, nenhum a priori para o aparecimento da sociedade, pois esta seria o resultado de decisóes, em geral racionais, que os indivíduos praticam procurando o melhor com o menor custo. Inúmeras correntes do pensamento social têm aqui suas raízes, todas elas convergindo para um utilitarismo que estaria na base do fenômeno social alimentado pelo homo economicus, capaz das melhores e das mais racionais decisóes frente aos fatos e variáveis que lhe aparecem. Se possível, esses teóricos almejariam que os conceitos sociológicos agregados fossem excluídos, ou então, que fossem tolerados apenas por conveniências da explicação. Independentemente dessa polêmica, os microfundamentos são importantes para a teoria macrossociológica porque ajudam a focalizar as questóes e enriquecer as respostas ${ }^{3}$.

Na Sociologia, embora haja controvérsias, Weber (1991) - com sua teoria da ação racional - , é lido como o principal teórico do individualismo, corrente paradigmática que se apresenta como antitética àquela de Durkheim (1974): o holismo. Considera-se aqui que haveria uma esfera analítica que, ao ser constituída historicamente, coloca-se acima da esfera individual. Ao contrário de pressupor que cada indivíduo possui empiricamente valor normativo, o holismo postula que a totalidade é que cria o indivíduo, agindo sobre o sentido de suas açôes. Trata-se, portanto, de uma outra construção paradigmática que se contrapóe ao individualismo. No holismo a totalidade social se diferencia da soma das partes (indivíduos), das quais tem uma autonomia relativa.

Percebemos, assim, que a oposição entre ambos paradigmas é fértil e contém inúmeros argumentos em razão das escolas de pensamento às quais diferentes autores se vinculam. De acordo com Caillé (1998, p. 10), "Se o holismo reifica e hipostasia a totalidade, o individualismo metodológico faz o mesmo com o indivíduo". Como sustentam Levine, Sober e Wright (1989), a Sociologia deve ser metodologicamente antirreducionista quando as propriedades e relaçóes que investiga surgem depois da análise feita. Esta, repetimos, é uma questão empírica, e não pode ser estabelecida por um decreto metodológico. 
Por outro lado, e dentro ainda do mesmo debate, a Sociologia na Universidade de Chicago dos anos 1930 cria um outro paradigma, o interacionismo simbólico, baseado em três premissas: 1) o modo como o indivíduo interpreta os fatos e age perante outros indivíduos ou coisas depende dos significados que ele atribui a esses outros indivíduos e coisas; 2) o significado é construído a partir do processo de interação social; e 3) os significados podem sofrer mudanças ao longo do tempo. (BLUMER, 1939) Percebemos assim que o foco do interacionismo simbólico é nos processos de interação social de indivíduos e grupos, mediados por relaçóes simbólicas. Pensamento e linguagem são para Blumer (1939) duas faculdades humanas mobilizadas nas interações sociais. $\mathrm{O}$ pensamento altera as interpretaçôes dos fatos, ao passo que a linguagem (verbal ou gestual) é um recurso constantemente empregado pelos indivíduos nos processos de interação social.

Diante destes paradigmas representativos das Ciências Sociais, observamos certos descompassos internos entre o "campo sociológico" mais amplo e aquele mais específico do estudo da infância, que passa a ser fortemente desenvolvido a partir dos anos 1980 do século passado ${ }^{4}$. Uma das principais críticas apresentadas pelos sociólogos da infância dizia respeito à falta de visibilidade da criança nas Ciências Sociais. Em resposta a esta ausência, Prout e James (1997, p. 5) inauguraram um novo paradigma para o estudo da infância, em suas palavras, "[...] mais como um potencial ou possibilidade do que um conjunto já realizado de postulados teóricos". E, de fato, o emergente paradigma agregou ideias já presentes nas escolas de pensamento sociológico a uma nova visão sobre a infância. Tomou do interacionismo a noção de criança como agente e ao mesmo tempo produto dos processos sociais; do construcionismo social ${ }^{5}$, destacou a variabilidade social, cultural e histórica da infância, negando a equivalência a uma dada realidade biológica. (JAMES; PROUT, 1997, p. x)

Os princípios deste paradigma voltam-se para o conceito de infância como uma construção social, ideia já defendida na década de 1960 por Ariès (1981). O fator inovador é que a infância passa a fornecer um quadro interpretativo para a compreensão dos primeiros anos de vida e que "[...] crianças não mais podem ser consideradas como apenas sujeitos passivos das determinaçóes estruturais". (JAMES; PROUT, 1997, p. 4)

Não deixamos de reconhecer que na pesquisa em Ciências Sociais, precisamente aquela interessada na temática aqui proposta, certas categorias de análise são fundamentais para situar a infância no contexto social. Nós nos referimos a aspectos como o próprio tamanho das cidades, a estrutura das classes sociais, questôes de gênero e etnia. São dimensóes que auxiliam a caracterização social da criança e ajudam a superar ideias equivocadas de naturalização da infância. Este ponto se relaciona com outra defesa do emergente paradigma (JAMES; PROUT, p. 3-4), que ao invés de considerar a criança como uma categoria de análise abstrata, passa a reconhecer que estudos históricos comparativos e transculturais podem 
evidenciar uma variedade de experiências de infância ao invés de um fenômeno natural, dissociado do contexto em que ela existe.

Esta breve síntese do debate sobre os paradigmas das Ciências Sociais e a inserção da criança como detentora de um lugar no social, sinaliza, portanto, novos enfoques analíticos. Tratar a criança e a cidade demanda retomar o que está na base do pensamento sociológico, que é a relação indivíduo vs. sociedade, mas também a tocar em outra variável, igualmente complexa, agência vs. estrutura. Tentando escapar dos binarismos, que sempre são reducionistas, preferimos lidar com a relação entre um e outro. $\mathrm{O}$ emergente paradigma defendido por James e Prout ajuda-nos a superar ideias binárias, e, principalmente naquilo que nos interessa mais de perto, favorece conexóes com os principais argumentos dos estudos urbanos.

\section{A relação infância e cidade}

A urbanização do mundo, acelerada sobretudo ao longo do século XX, evidenciou problemas que passaram a fazer parte do cotidiano das maiores cidades: desigualdade social, violência, desordem urbana, dentre outros. Essa é apenas uma de suas facetas. Isto porque as cidades também promovem novas sociabilidades, respondendo às pressóes oriundas de um cotidiano complexo e heterogêneo ${ }^{6}$. Seus espaços favorecem o encontro de diferentes grupos, viabilizado pela proximidade física entre eles.

Ao refletir sobre a vida urbana, Simmel (1974) estabeleceu diferenças expressivas quando a tratamos a partir do tamanho populacional. $\mathrm{O}$ autor contrapóe características psicológicas e culturais de habitantes de metrópoles ou grandes centros urbanos às daqueles que vivem em pequenos centros ou ambientes rurais. Nas metrópoles desponta um indivíduo particular que age muito mais pelo cérebro do que pela emoção, esta uma característica reservada aos habitantes de pequenos núcleos. Nas metrópoles, a impessoalidade é a principal característica, dada a extrema racionalização do cotidiano produzida pela modernidade urbana.

A segurança garantida pelo núcleo familiar ampliado se rompe na metrópole dada a enorme diferenciação de indivíduos nela presentes. Esta heterogênea composição individual e social transforma a cidade em terreno de incerteza e insegurança. Outro fator presente, a hostilidade latente do espaço urbano, faz com que as crianças ainda tenham seus mecanismos de usos da cidade restringidos. Evidente que se trata aqui do espaço público, onde é raro encontrar crianças desacompanhadas de adultos. Esta faceta da cidade é lida como reticente à presença de crianças sem o acompanhamento do adulto responsável, situação reforçada pela mídia que privilegia matérias focando os perigos da cidade, que ameaçam a inte- 
gridade física de seus habitantes. Uma concepção de criança como ser desprovido de autonomia termina sendo reforçada por esta representação midiática do espaço público urbano ${ }^{7}$.

Por outro lado, a vida na cidade motiva diferentes experiências da criança no uso e apropriação do espaço. É esperado que na cidade "[...] jovens e crianças buscam ser si mesmos, numa tentativa inédita de independência e autonomia ante os pais, diante das suas primeiras identificaçóes e raízes [...]". (CASTRO, 2004, p. 35, grifo da autora) Ou seja, a cidade suscita aprendizagens tanto individuais, únicas, mas também compartilhadas na experiência urbana.

A Sociologia Urbana vem buscando ultrapassar as alternativas teóricas já tradicionais, partindo de uma perspectiva que se aproxima daquela sugerida por Simmel (1974), para quem a cidade era sobretudo um lugar de alteração da dimensão cognitiva do cidadão. É interessante lembrar como Simmel toma por objeto de reflexão a relação sociedade vs. indivíduo. Para ele essa relação se caracteriza por um vaivém constante entre o individual e o social, através daquilo que ele chama de "ação recíproca", isto é, a influência que cada um exerce sobre o outro. Para Simmel (1974), o indivíduo e o social não são dados fixos, mas "formas moventes", e daí porque ele prefere tratar de socializaçáo ao invés de sociedade ${ }^{8}$.

Forçado pela necessidade de gerir quantidades crescentes de fluxos de informações e de um tempo cada vez mais acelerado, o indivíduo urbano é levado a construir uma nova equação espaço-tempo. Assim, o espaço físico da cidade deixa de ser tratado como um objeto externo que se organiza em função das necessidades e expectativas dos agentes, passando a ser tratado como um fenômeno dinâmico em permanente redefinição, dadas as ações dos indivíduos que nele habitam e que o constroem dia após dia.

Anteriormente, há ainda a adequação de "fato social total", de Mauss (1961), para definir a cidade, na qual a atividade econômica constitui apenas uma das partes da troca geral e onde a troca de bens materiais vale tanto quanto a troca de gentilezas, festas, sorrisos. Ou seja, a valorização do simbólico na conformação dos vínculos sociais e da sociedade como um todo se manifesta explicitamente. Escreve Mauss (1961, p. 294): “[...] já faz algum tempo que Durkheim e eu ensinamos que não se pode comunicar senão por símbolos [...] e que pensamos que uma das características do fato social é, justamente, o seu aspecto simbólico.”

Assim, se focarmos apenas na esfera da economia na definição de cidade corremos o risco de nuances do fenômeno. De fato, a nossa questão de fundo é saber o que altera as interaçóes sociais, o fato de estarmos imersos numa aglomeração de pessoas e atividades - a cidade - e, nesse contexto, qual a influência sobre os modos de vida das crianças.

Cabe recuperar, portanto, a definição sociológica de cidade elaborada por Wirth (1973), um dos expoentes da Escola de Chicago que se debruçou sobre 
o entendimento do fenômeno urbano na primeira metade do século XX. Escreve o autor (1973, p. 96): “[...] para fins sociológicos, uma cidade pode ser definida como um núcleo relativamente grande, denso e permanente de indivíduos, socialmente heterogêneos". A definição de Wirth tem na natureza heterogênea do espaço social urbano um dos principais indicadores de sua manifestação. A heterogeneidade termina sendo uma característica de base, a partir da qual se definiria a característica essencial da sociedade urbana. A cidade termina sendo um aglomerado de pessoas e de culturas, resultando assim num emaranhado de tipos humanos e sociais. Há que se acrescentar ainda que grandes números populacionais terminam gerando uma maior variedade de tipos individuais, inclusive de diferentes faixas etárias.

Os estudos teóricos sobre a infância, nesse aglomerado heterogêneo, encontram-se em desenvolvimento, mas ainda pouco consolidados em uma linha de pesquisa, como se a criança pouco existisse no cotidiano do mundo social da cidade. Talvez isso possa ser explicado pela própria definição de indivíduo na tradição das Ciências Sociais, categoria que pressuporia, dentre outras características, autonomia face às condições gerais da existência. Em outro sentido, Castro (2004, p. 19) sugere uma relação bidirecional entre cidade e infância, ao escrever que

Recebem-na como obra dada pelos adultos cuja vida aparece para eles como arbitrária e imune à ação humana. Entretanto, como o guerreiro que parte para a batalha, a criança e o jovem se lançam à conquista da cidade.

O próprio Wirth considera que a multiplicação de pessoas em estado de interação sob condiçóes que tornam impossível seu contato como personalidades completas não anula indivíduos adultos da mesma maneira que anula crianças. Entretanto, crianças jamais se tornariam invisíveis no espaço urbano, pois elas se apresentam ao mundo social entre estranhos na cidade da mesma forma que adultos. Esse tratamento aparentemente similar dado à criança e ao adulto no ambiente público e heterogêneo da cidade reflete, para o caso da criança, a percepção de um ser dependente e incapaz de açóes autônomas e pertinentes ao seu mundo. Naturaliza-se assim essa incompetência em agir em sociedade e torna o adulto o seu representante racional diante do mundo social. E é justamente na contracorrente deste argumento que a próxima seção se voltará.

\section{As possibilidades de interação na cidade}

Em busca de análises sobre os diversos fenômenos sociais, a Sociologia foca as interrelações humanas. Desde os clássicos sabemos que a vida em sociedade tanto promove como resulta de interação, pensamento este reiterado pelos grandes 
pensadores do campo social, tais como Goffman, Bourdieu, Caillé, entre outros. Assim, interagir com o mundo adulto ou mesmo com as outras crianças de sua entourage é um fenômeno social cuja lógica é passível de decodificação. Interessa-nos entender qual a posição que o espaço urbano ocupa entre as diferentes possibilidades de interação. Assim, temos duas variáveis-chave que merecem ser discutidas para o alcance de nossos objetivos: espaço urbano (cidades) e interaçóes sociais da criança.

Cidades foram criadas e planejadas pelos adultos, de modo que suas necessidades fossem supridas. É igualmente evidente que adultos possuem uma circulação mais livre e autônoma do que crianças na cidade. Entretanto, de acordo com Ward (1978, p. 204), cidades poderiam ser transformadas em lugares onde crianças e adultos vivem - e poderíamos agregar, interagem - juntos.

Giddens (2001, p. 80) define interação social como “[...] o processo pelo qual agimos e reagimos em relação a todos que estão a nossa volta”. A interação enquanto objeto de estudo se deixa identificar: segundo Goffman (1989) se trata desta classe de acontecimentos que tem lugar quando de uma presença conjunta e em virtude dessa presença conjunta. Para o autor, a interação se torna concreta na medida em que os agentes em questão dominam os códigos sociais que a organiza. Particularmente, ao pensar na relação da criança com o espaço público da cidade, é possível estabelecer uma conexão com dois outros conceitos importantes da obra de Goffman (2010), quais sejam, o de interaçóes focadas e o de interações não-focadas.

Ao retomar a obra de Goffman, Giddens (2001, p. 91-92) explica que interaçóes não-focadas ocorrem quando indivíduos têm consciência da presença dos demais, o que ocorre nas ruas, parques ou mesmo filas de espera dos ambientes urbanos. Em tais interaçóes, a comunicação é estabelecida de forma não-verbal, mas através da linguagem gestual. As interaçôes focadas, por sua vez, se dão quando os indivíduos percebem diretamente o que os outros dizem ou fazem. Em geral, o espaço público na cidade, heterogêneo por natureza, termina por aproximar indivíduos em razão do domínio que detêm desses códigos interacionais e distanciar os que comungam de códigos distintos. Interaçóes de crianças e adultos e crianças com seus pares, na cidade, envolvem o tempo todo trocas focadas e não-focadas.

Elias (1994) alerta-nos para a importância de definir o indivíduo sociológico que pressupóe considerar as características objetivas de sua existência. $\mathrm{Na}$ Sociologia todos temos, entre outros atributos, cor, etnia, gênero, classe social, que, de acordo com Prout e James (1997, p. 8), são variáveis da análise social - assim como o é a própria infância - que não devem ser jamais inteiramente separadas. Sáo atributos que no conjunto oferecem o desenho identitário de cada membro da sociedade. Análises empíricas nos auxiliam a delimitar os espaços identitários 
individuais, explicando o grau relativo de autonomia que todos temos, adultos e crianças, quando inseridos num contexto social.

Ao mesmo tempo, a máxima Diga-me onde moras, e identifico sua posição na estrutura social aponta o lugar do espaço físico na determinação do lugar social. Se assim o é, cada lugar ocupado no espaço social detém maiores ou menores possibilidades de se apropriar do espaço urbano, inclusive pelas crianças. Bourdieu (1994) enxerga na cidade algo mais amplo que uma economia de trocas mercantis, aquilo que ele chama de trocas simbólicas. A sociedade aqui aparece como fenômeno que se objetiva e se incorpora nos indivíduos e classes através de certos dispositivos, como crenças e valores, que explicam seus funcionamentos simbólicos e econômicos em coletividade. É essa dimensão simbólica que facilita a inserção ativa de crianças nas interaçóes sociais que ocorrem em espaços urbanos.

Consideremos a socialização um processo decorrente das interações sociais, que começa na infância e se estende ao longo da vida e se apoia, em parte, no ensino e também na aprendizagem latente de formas consideradas evidentes de relacionamento com os outros. Entre a Psicologia - que centrava suas interpretaçóes da socialização como processo de interação particularmente nas relaçóes intrafamiliares na infância (sobretudo nas relaçóes mãe-filho) -, e a Antropologia que vai tratá-la enquanto processo de transmissão da cultura em sociedades pequenas e relativamente homogêneas, a Sociologia se debruça sobre o papel das instituiçóes e das subculturas em sociedades complexas como agentes da socialização ?

Baseado nas reflexôes emitidas até aqui consideramos que discutir a relação entre infância e cidade pressupóe o espaço urbano como elemento formador da individualidade das pessoas simultaneamente à construção de sua autonomia. Nesse processo, o essencial é agregar à análise a proximidade que a cidade impóe e os seus impactos nessa dupla tarefa de individualização e socialização que é qualitativamente diferente no meio urbano. É nas cidades que o jogo classificatório entre indivíduos e grupos, que cria os status sociais, se manifesta claramente; é nesse jogo entre proximidade física e distância social que os efeitos da coabitação no espaço da cidade se apresenta com mais evidência, apontando assim para a variável física da aglomeração que passa a intervir nos processos interacionais.

É nesse sentido que ao tratar de proximidade física e distância social, Velho (2008) ilustra situações cotidianas de encontros com distintas personagens urbanas (nordestinos, surfistas, domésticas, senhoras, militares), e argumenta que ainda que haja familiaridade entre todas elas, esta não é homogênea. São personagens que fazem parte de uma mesma sociedade, são contemporâneas e vizinhas, mas estabelecem aproximaçóes diferenciadas. Aqui há pistas importantes para o pesquisador, já que tanto infância como cidade são temas familiares, mas que devem ser bem conhecidos através de ferramentas teóricas potentes, que evitem análises já aceitas no senso comum ${ }^{10}$. 
$\mathrm{Na}$ relação entre infância e cidade, como vimos, a esfera onde se situariam as reflexóes é a do espaço público. Em geral o uso do espaço público se faz pela oportunidade de usufruir aquilo que a cidade oferece mediante diferentes interações. Para crianças é sobretudo o desejo de "explorar tudo que o ambiente pode oferecer" (WARD, 1978, p. 210), pressupondo um lugar que admite uma reunião informal de pessoas, cada um com seu próprio ritmo e onde a coerência vem precisamente desta parte semi-institucionalizada. (CHALAS, 2000)

$\mathrm{Na}$ cidade o que está em questão é a possibilidade do incerto, do imprevisto sem risco. É quando a influência é recíproca e nos encontramos numa situação de interação, na medida em que a percepção do sujeito é modificada pela expectativa de uma reciprocidade. A noção de reciprocidade implica aquela de feedback e a interação social é uma relação de coexistência.

Precisamos atentar, contudo, para a naturalização de uma relação de poder, que associa de forma imperativa o uso do espaço urbano quase exclusivamente ao adulto. Por deterem um discurso de proteção às crianças, os adultos facilmente as excluem da cidade, restringindo as interaçóes de ambos ao espaço privado ou a lugares previamente demarcados no espaço público. Estes espaços, tomados pelos adultos como os mais adequados às crianças e que geralmente se voltam ao lúdico, dificilmente promovem interações mais diversificadas.

Ao analisar aspectos do cotidiano das cidades americanas nos anos 1940/1950, Jacobs (1992) apresentou equívocos em seu planejamento, sobretudo quando se organizam em fragmentos e buscam a homogeneização. A autora chama a atenção para a inclinação dos adultos tomarem os parques como lugares protegidos para as crianças, em contraposição à rua. Seu argumento é de que a substituição das ruas pelos parques causaria a falta de contato com outras geraçóes e evitaria possíveis interaçóes e encontros, no sentido de Goffman (1989).

Por fim, retomamos o argumento de que cidades podem oferecer experiências ricas às crianças, e para isto, as mais diferentes interações são fundamentais. Ward (1978) e Jacobs (1992) se alinham quando criticam a cidade fragmentada, que exclui o encontro de diferentes grupos e pessoas. Ward (1978, p. 204) reitera a busca pela "cidade compartilhada" entre adultos e crianças, e novamente concorda com Jacobs ao afirmar que "a verdade última é que crianças brincam em qualquer e todo o lugar".

\section{Considerações finais}

As Ciências Sociais se baseiam em paradigmas consolidados e, de acordo com o mapeamento que apresentamos, não deixaram muito espaço para a construção de novos olhares sobre a criança e sua relação com a cidade. Isto se deve, em 
parte, ao reconhecimento tardio, preponderantemente a partir dos anos 1980, da criança enquanto agente ativo dos seus mundos sociais. Lembremos que a infância é uma experiência bastante curta se levarmos em conta o tempo médio de vida de um indivíduo, mas que, socialmente, trata-se de uma forma estrutural permanente da sociedade, independentemente das transformaçóes de seus membros e concepçóes. (QVORTRUP, 1987; QVORTRUP et al, 1994)

Vimos ao longo do texto que o espaço público da cidade se apresenta como um dos fatores responsáveis pela redução das distâncias sociais, pois favorece o encontro de diferentes grupos, viabilizado pela proximidade física entre eles. Ao mesmo tempo, dada a natureza heterogênea de indivíduos que circulam pelos espaços públicos urbanos, há mecanismos de seleção das interaçóes sociais que porventura possam aí ocorrer. Tais mecanismos se sustentam na comunhão de códigos comuns que aproximam as pessoas e afastam aqueles que não compartilham os mesmos pressupostos interacionais. Particularmente no que se refere ao domínio do espaço público urbano pelas crianças agrega-se ainda uma dificuldade a mais: a naturalização de sua incompetência em agir socialmente.

Assim, as reflexóes que desenvolvemos nos mostram, por um lado, uma relação de poder do adulto sobre a criança que se apresenta disfarçadamente como proteção face às incertezas presentes no espaço da cidade. Por outro lado, argumentamos que as diversas experiências e interaçóes da criança na cidade são fundamentais para o seu processo de socialização. Não se trata aqui de defender a plena autonomia de uma criança no espaço urbano, pois seria ingênuo abstrairmos as dificuldades e riscos que isso acarretaria. Porém, temos claro que é necessário romper com a imagem difundida de que a cidade apresenta mais perigos do que possibilidades às crianças.

Se retomarmos o argumento de que "sociedade é interação" (GOFFMAN, 1989) retiramos da criança um espaço de largas possibilidades de enfrentar o novo com os riscos que este traz, para todos, inclusive os adultos. Claro que alterar esse senso comum é um árduo trabalho de desconstrução da leitura que se faz sobre o espaço urbano como lugar da incerteza, da violência e do medo. Trata-se também de desnaturalizar a imagem de dependência em todos os níveis da criança em relação ao adulto. E está justamente aí a possibilidade de construirmos nos campos da Sociologia e da Educação uma sólida linha de pesquisa sobre a infância e a cidade.

\section{Notas}

1. Trabalhos pioneiros importantes realizados tanto na Europa (QVORTRUP et al, 1994; JAMES, PROUT, 1997; JAMES, JENKS, PROUT, 1998) quanto nos Estados Unidos (CORSARO, 1997) tem enfrentado as teorias clássicas da Sociologia, apresentando novos repertórios teóricos e metodológicos ao estudo da infância, que se distanciam das definiçóes sobre socialização. Atualmente, os 
estudos da infância estão plenamente desenvolvidos e consolidados, defendendo uma abordagem interdisciplinar. No Brasil são evidentes os esforços de pesquisadores, sobretudo da área de Educação, para consolidarem o campo de estudos da infância a partir de referenciais das Ciências Sociais, o que é explicitado em Nascimento et al (2013).

2. Referimo-nos à obra A estrutura das revoluçöes científicas, publicada originalmente em 1962, onde o autor faz uma reflexáo sobre a história da ciência e a dinâmica de sua evoluçáo, sendo um marco na Sociologia do Conhecimento.

3. De qualquer maneira, passar das instituiçóes sociais e dos padrôes agregados de comportamento para os indivíduos "[...] é uma operaçâo semelhante à passagem das células às moléculas" e "[...] a descrição correta de um indivíduo pode implicar a referência a outros" (ELSTER, 1985, p. 5-6). Guarda-se, então, o princípio da interação como explicativo da sociedade.

4. Veja-se Sirota (2001) para uma revisão sobre a emergência da Sociologia da Infância.

5. Embora chame atençâo para a falta de consenso na Sociologia, Giddens (2001, p. 98) explica que a abordagem teórica do construcionismo social acredita "[...] que o que indivíduos e sociedade entendem como realidade é uma criação da interação social de indivíduos e grupos".

6. Perspectiva de análise considerada historicamente pelos intelectuais da Escola de Chicago na primeira metade do século passado, que entendiam a cidade como um "laboratório social".

7. As estatísticas mostram que a maioria da violência contra a criança tem no espaço doméstico seu principal território de ação. No espaço público, em geral, a criança é bem menos atingida por atos violentos. Para maiores informaçóes, leia-se Waiselfisz (2012).

8. Mais detalhes sobre essa discussão em Vocabulaire de Psycosociologie (BARUS et al, 2002), especialmente o verbete Interaction.

9. Esta definição geral vem do Dicionário do pensamento social do século XX (OUTHWAITE, 1996) e consideramos que atende aos propósitos desse artigo. Entretanto, existem análises bem mais sofisticadas sobre o fenômeno que não serão recuperadas aqui.

10. Cabe ressaltar o fato de que o manuseio da linguagem falada pelo adulto é diferente daquele das crianças. Seria necessário decodificar os significados que as crianças dấo às suas experiências e que extrapolam a linguagem usual do adulto.

\section{Referências}

ARIÈS, P. História Social da Criança e da Família. 2. ed. Rio de Janeiro: LTC, 1981.

BARUS, J. et al. Vocabulaire de psychosociologie: reférences et positions. Paris: Érès, 2002.

BLUMER, H. Collective Behaviour. In.: PARK, R. (Ed.) An outline of the principles of sociology. New York: Barnes\&Noble, 1939. p. 221-280.

BOURDIEU, P. Raisons pratiques: sur la théorie de l'action. Paris: Editions du Seuil, 1994. - O poder simbólico. Rio de Janeiro: Bertrand Brasil, 2007.

BRASIL. Estatuto da Criança e do Adolescente. Lei Federal 8.069 de 13/07/1990. 
CAILlÉ, A. Nem holismo nem individualismo metodológicos: Marcel Mauss e o paradigma da dádiva. Revista Brasileira de Ciências Sociais, São Paulo, v.13, n. 38, p. 5-38, out. 1998. Disponível em http://www.scielo.br/scielo.php?script=sci arttext\&pid =S0102-69091998000300001. Acesso em $11 \mathrm{dez} .2013$.

CHALAS, Y. L'invention de la ville. Paris: Anthropos, 2000.

CASTRO, L.R. A aventura urbana: crianças e jovens no Rio de Janeiro. Rio de Janeiro: 7 Letras, 2004.

CHRISTENSEN, P.; O'BRIEN, M. Children in the city: introducing new perspectives. In.: (Eds). Children in the City: home, neighbourhood and community. London/NewYork: Routledge Falmer, 2003. p. 1-12.

CORSARO, W. The sociology of childhood. California: Pine Forge, 1997.

ELIAS, N. A sociedade dos individuos. Rio de Janeiro: Zahar, 1994.

ELSTER, J. Making sense of Marx. Cambridge: Cambridge University Press, 1985.

GIDDENS, A. Sociology. Cambridge: Polity Press, 2001.

GOFFMAN, E. A representação do eu na vida cotidiana. Petrópolis: Vozes, 1989.

Comportamento em lugares públicos: notas sobre a organizaçáo social dos ajuntamentos. Petrópolis: Vozes, 2010.

JAMES, A.; PROUT, A. Introduction. In.: . (Eds). Constructing and reconstructing childhood. London: Falmer Press, 1997. p. 1-6.

JAMES, A.; PROUT, A. (Eds). Constructing and reconstructing childhood. London: Falmer Press, 1997.

JAMES, A.; JENKS, C.; PROUT, A. Theorizing childhood. Cambridge: Polity Press, 1998. INSTITUTO BRASILEIRO DE GEOGRAFIA E ESTATÍSTICA. Censo Demográfico 2010. Brasília, 2010.

LEVINE, A.; SOBER, E.; WRIGHT, E. O. Marxismo e individualismo metodológico. Revista Brasileira de Ciências Sociais, São Paulo, v. 4, n. 11, p. 57-70, out. 1989. Disponível em http://www.anpocs.org.br/portal/publicacoes/rbcs $00 \quad 11 / \mathrm{rbcs} 11 \quad 04 . \mathrm{htm}$. Acesso em 10 Mai. 2014.

MAUSS, M. Sociologie et anthropologie. Paris: PUF, 1961.

NASCIMENTO, M.L. et al. Infância e sociologia da infância: entre a invisibilidade e a voz. São Paulo: FEUSP, 2013.

OUTHWAITE, W. Dicionário do pensamento social do século XX. Rio de Janeiro: Zahar, 1996.

PROUT, A.; JAMES, A. A new paradigm for the Sociology of Childhood? Provenance, promise and problems. In.: JAMES, A.; PROUT, A. (Eds). Constructing and reconstructing childhood. London: Falmer Press, 1997. p. 7-33. 
PROUT. A. Preface. In: CHRISTENSEN, P.; O`BRIEN, M. (Eds). Children in the City: home, neighbourhood and community. London/NewYork: Routledge Falmer, 2003, p. $\mathrm{xV}$-xvi.

QVORTRUP, J. Introduction. The Sociology of Childhood. International Journal of Sociology, London, v. 17, n. 3, p. 3-37, Fall 1987. [Special Issue].

. Childhood matters: an introduction. In: QVORTRUP, J. et al. Childhood matters: social theory, practices and politics. Aldershot: Avebury, 1994. p. 1-23.

QVORTRUP, J. et al. Childhood matters: social theory, practices and politics. Aldershot: Avebury, 1994.

SIMMEL, G. A metrópole e a vida mental. In: VELHO, O. (Org.) O fenômeno urbano. Rio de Janeiro: Zahar, 1974.

SIROTA, R. Emergência de uma sociologia da infância: evolução do objeto e do olhar. Cadernos de Pesquisa, São Paulo, n. 112, mar. 2001. Disponível em http://www.scielo.br/ pdf/cp/n112/16099.pdf. Acesso em 14 Mai. 2014.

VELHO, G. Observando o Familiar. In: Individualismo e Cultura: notas para uma Antropologia da Sociedade Contemporânea. 8. ed. Rio de Janeiro: Zahar, 2008. p. $122-134$.

WAISELFISZ, J.J. Mapa da violência 2012: crianças e adolescentes do Brasil. Rio de Janeiro: Centro Brasileiro de Estudos Latino-Americanos/Flacso, Rio de Janeiro, 2012. Disponível em http://www.mapadaviolencia.org.br/pdf2012/MapaViolencia2012 Criancas e Adolescentes.pdf. Acesso em 10 Mai. 2014.

WARD, C. The child in the city. New York: Pantheon Books, 1978.

WEBER, M. Conceitos sociológicos fundamentais. In: Economia e sociedade. Brasília: EDUnB, 1991. v. 1. p. 3-27.

WIRTH, L. O urbanismo como modo de vida. In: VELHO, O. (Org.) O fenômeno urbano. Rio de Janeiro: Zahar, 1967. p. 97-122.

Recebido em 15 de maio de 2014.

Aprovado em 24 de outubro de 2014. 